\title{
Following cytotoxic nanoconjugates from injection to halting the cell cycle machinery and its therapeutic implications in oral cancer
}

Hend M. Abdel Hamid 1*, Zeinab E. Darwish', Sahar M. Elsheikh', Ghada M. Mourad ${ }^{2,3}$, Hanaa M. Donia ${ }^{4}$ and Marwa M. Afifi ${ }^{1,5^{*}}$ (D)

\begin{abstract}
Background: The concept of personalized therapy has been proven to be a promising approach. A popular technique is to utilize gold nanoparticles (AuNPs) as drug delivery vectors for cytotoxic drugs and small molecule inhibitors to target and eradicate oral cancer cells in vitro and in vivo. Both drug and nanocarrier designs play important roles in the treatment efficacy. In our study, we standardized the nanosystem regarding NPs type, size, surface ligands and coverage percentage leaving only the drugs mode of action as the confounding variable. We propose that similarly constructed nanoparticles (NPs) can selectively leverage different conjugated drugs irrelevant to their original mode of action. If proven, AuNPs may have a secondary role beyond bypassing cancer cell membrane and delivering their loaded drugs.

Methods: We conjugated 5- fluorouracil (5Fu), camptothecin (CPT), and a fibroblast growth factor receptor1inhibitor (FGFR1i) to gold nanospheres (AuNSs). We followed their trajectories in Syrian hamsters with chemically induced buccal carcinomas.

Results: Flow cytometry and cell cycle data shows that 5Fu- and CPT- induced a similar ratio of S-phase cell cycle arrest as nanoconjugates and in their free forms. On the other hand, FGFR1i-AuNSs induced significant sub-G1 cell population compared with its free form. Despite cell cycle dynamics variability, there was no significant difference in tumor cells' proliferation rate between CPT-, 5Fu- and FGFR1i- AuNSs treated groups. In our in vivo model, FGFR1i-AuNSs induced the highest tumor reduction rates followed by 5Fu- AuNSs. CPT-AuNSs induced significantly lower tumor reduction rates compared with the 5Fu- and FGFR1i- AuNSs despite showing similar proliferative rates in tumor cells.

Conclusions: Our data indicates that the cellular biological events do not predict the outcome seen in our in vivo model. Furthermore, our results suggest that AuNSs selectively enhance the therapeutic effect of small molecule inhibitors such as FGFR1i than potent anticancer drugs. Future studies are required to better understand the underlying mechanism.
\end{abstract}

Keywords: Gold nanoparticles, 5-flourouracil, Camptothecin, FGFR1 inhibitor, Oral cancer

\footnotetext{
*Correspondence: hend.sadek@alexu.edu.eg; marwa.afifi@nih.gov

'Oral Pathology Department, Faculty of Dentistry, Alexandria University, Champilion Street, Azarita, Alexandria, Egypt

Full list of author information is available at the end of the article
}

(c) The Author(s). 2021 Open Access This article is licensed under a Creative Commons Attribution 4.0 International License, which permits use, sharing, adaptation, distribution and reproduction in any medium or format, as long as you give appropriate credit to the original author(s) and the source, provide a link to the Creative Commons licence, and indicate if changes were made. The images or other third party material in this article are included in the article's Creative Commons licence, unless indicated otherwise in a credit line to the material. If material is not included in the article's Creative Commons licence and your intended use is not permitted by statutory regulation or exceeds the permitted use, you will need to obtain permission directly from the copyright holder. To view a copy of this licence, visit http://creativecommons.org/licenses/by/4.0/ The Creative Commons Public Domain Dedication waiver (http://creativecommons.org/publicdomain/zero/1.0/) applies to the data made available in this article, unless otherwise stated in a credit line to the data. 


\section{Background}

The concept of cancer nanotechnology emerged as a hope to enhance chemotherapeutic drugs biodistribution, minimize off-target effects and enhance uptake in malignant cells [1]. Numerous studies reported the enhanced therapeutic effect against oral squamous cell carcinoma (OSCC) using a variety of nanoparticles, cytotoxic drugs and cancer models [2-5]. Accordingly, it is well accepted that nanocarriers act as vehicles to deliver drugs to their targets. For example, polyethylene glycol (PEG) coated nanocarriers play a critical role in overcoming opsonization and subsequent elimination from the blood stream [6]. Moreover, nanoparticles actively target oral cancer cell receptors such as surface integrins $\alpha v \beta 6$ by peptides such as Arginyl-glycylaspartic acid (RGD) [7]. Both drug and nanocarrier designs play important roles in the treatment efficacy. Generally, the drug is designed to formulate compounds that inhibit cancerous cell proliferation, while the nanocarrier design aims to develop nano-vehicle structures that maximize drug concentration in the tumor relative to healthy tissue, thus reducing adverse drug effects [8]. We propose that similarly constructed nanoparticles (NPs) can selectively leverage different conjugated drugs irrelevant to their original mode of action. In our study, we standardized the nanosystem regarding NPs type, size, surface ligands and coverage percentage leaving only the drugs mode of action as the confounding variable. To confirm our hypothesis, we chose 5-fluorouracil $(5 \mathrm{Fu})$ and camptothecin $\mathrm{CPT}$ as cytotoxic drugs. Both drugs are used in treatment protocols of OSCC. Moreover, 5Fu and CPT interfere with DNA and RNA synthesis inhibiting $\mathrm{S}$ phase of the cell cycle via 2 different mechanisms. $5 \mathrm{Fu}$ is an antimetabolites cytotoxic drug, it interferes with nucleoside metabolism by incorporation into RNA and DNA molecules, leading to cytotoxicity and cell death. However, CPT is a plant alkaloid drug inhibits topoisomerase I enzyme activity required for DNA molecule integrity during replication $[9,10]$. Then, we compared $5 \mathrm{Fu}$ and $\mathrm{CPT}$ cytotoxic effects to a small molecule inhibitor targeting fibroblastic growth factor receptor 1 (FGFR1). Following which, we synthesized average size $(\sim 30 \mathrm{~nm})$ gold nanospheres (AuNSs) and sequentially coated their surface with ligands such PEG, RGD peptide, cytotoxic drugs $5 \mathrm{Fu}$ and CPT, or fibroblastic growth factor receptor 1 inhibitor (FGFR1i). This was performed using the same surface coverage ratio and chemical linker. At the end of the synthesis/conjugation phase, we assembled 3 nano-constructs, PEG-RGD-5FuAuNSs; PEG-RGD-CPT-AuNSs; and PEG-RGD-FGFR1iAuNSs. Meanwhile, we chemically induced hamster buccal pouch carcinoma (HBPC) and injected the animals intraperitoneally with the corresponding nanoconjugates. We used the free forms of $5 \mathrm{Fu}, \mathrm{CPT}$ and FGFR1i molecules as controls since their impact on cellular functions is well reported [11-14].

Following trajectories of the drug nanocarriers in our in vivo model, we found a heterogeneity in the underlying events leading to the final tumor reduction outcome. For example, 5Fu-AuNSs and FGFR1i-AuNSs had similar tumor reduction rates but different cell cycle dynamics. On the other hand, CPT-AuNSs and 5FuAuNSs had the same cell cycle dynamics but significantly different tumor volume reduction and global impact. Moreover, our findings show that conjugating a small molecule inhibitor, FGFR1i, to AuNSs induced the most favorable therapeutic outcome against OSCC compared with 5Fu-ANSs and CPT-AuNSs.This was rather surprising given how potent these drugs are even as free molecules. Our data suggests that AuNSs selectively enhance the therapeutic effect of small molecule inhibitors such as FGFR1i than potent anticancer drugs indicating that gold nanoparticles (AuNPs) play a greater role than only acting as cargo-carriers. If proven, AuNPs may have a secondary role beyond bypassing cancer cell membrane and delivering their loaded drugs.

\section{Methods \\ Gold nanoparticles synthesis, characterization and functionalization}

Using the citrate reduction method, we synthesized gold nanospheres (AuNSs, Chloroauric acid, Sigma Aldrich, $2,554,169$, Germany) with an average diameter of $30 \mathrm{~nm}$ [15]. Briefly, $50 \mathrm{ml}$ of $0.1 \%$ auric acid solution was heated while stirring until boiling. Then, $10 \mathrm{ml}$ of $1 \%$ tri-sodium citrate was added with vigorous stirring. The solution continued to boil for 15 min to finally obtain the desired particle size/shape. To enhance AuNSs properties, we performed several surface modifications to functionalize the synthesized nanoparticles with the proper ligands.

Using a mono-layer percent coverage approach, we functionalized AuNSs with poly-ethylene glycol (PEG), a polymer used for further stabilization and to evade plasma protein opsonization in vivo $[2,6]$. We added $1.0 \mathrm{mM}$ solution of PEG $5000 \mathrm{MW}$ (Sigma Aldrich, 1, 546,580 , Germany) dissolved in deionized water $\left(\mathrm{diH}_{2} \mathrm{O}\right)$ to AuNSs solution to achieve a molar ratio equivalent to $20 \%$ of surface coverage (ca. $565.56 \mathrm{~mol}$ of PEG were added per particle). Using the same approach, we further conjugated AuNSs with a custom peptide (RGD) that targets alpha and beta integrins expressed abundantly on the surface of OSCC cells. We dissolved $0.93 \mathrm{mM}$ Arginylglycylaspartic acid (RGD, GenScript, USA Inc.) in $\mathrm{diH}_{2} \mathrm{O}$ which was immediately added to the PEG-AuNSs solution to achieve $25 \%$ surface coverage (ca. $706.95 \mathrm{~mol}$ of RGD were added per particle). Finally, we divided the PEG-RGD-AuNSs solution into 3 batches, where we further conjugated the drugs to the AuNSs via a $\mathrm{pH}$ - 
sensitive hydrazone linkage by methyl thioglycolate and hydrazine using a previously published method [16]. Final nano-conjugates were as follows, PEG-RGD-5FUAuNSs, PEG-RGD-CPT-AuNSs, and PEG-RGD-FGFR1iAuNSs. To establish this, we added $1.0 \mathrm{mM}$ solution of 5FU, CPT (Selleckchemicals, S2045, S1288, respectively), or PD173074 (Sigma Aldrich, P2499, Germany) separately to PEG-RGD-AuNSs to accomplish a molar ratio equivalent to cover $55 \%$ of the surface (ca. $1555.29 \mathrm{~mol}$ of the drug were added per particle). For the EGFR1-i, we dissolved the inhibitor in dimethyl sulfoxide (DMSO) by $10 \mathrm{mg} / \mathrm{ml}$. Then $100 \mu \mathrm{l}$ from the working solution was dissolved in $1.9 \mathrm{ml}$ glycrol according to the manufacturing protocol.

To make sure that our synthesis and functionalization processes were successful, we used transmission electron microscopy (TEM, JOEL, 1400plus, Japan) and the Nano-Zetasizer (Malvern Instruments, Worcestershire, UK) to confirm the size and morphology of the synthesized AuNSs. We took measurements before, during, and after conjugation to compare changes in size and surface charges. This is critical, since the interaction of AuNSs with the biological environment and biocompatibility depends on their surface charge [17]. We also measured the absorption spectra of the different nanoconjugates using a UVVIS spectrophotometer (The Thermo Scientific ${ }^{\text {TM }}$ Evolution 300, USA) at $530 \mathrm{~nm}$ to quantify the distribution of AuNSs.

After successfully synthesizing the nano-constructs, we wanted to confirm that the chemical linker joining the drugs to AuNSs was $\mathrm{pH}$ - sensitive. This is important because when the particles get taken up by cells, the acidic $\mathrm{pH}$ in the lysosomes breaks the chemical linker and induces drug release. To measure $\mathrm{pH}$ sensitivity, we added an acidic buffer solution $(\mathrm{pH}=5)$ to the nanoconjugates solutions and allowed them to shake for 5 mins at $37^{\circ} \mathrm{C}$. After which the solutions were centrifuged for $10 \mathrm{~min}$ at $6000 \mathrm{rpm}$. The absorbance peak of the supernatant was measured using a UV-VIS spectrophotometer (DeNovix DS-11 FX +). If the linker is $\mathrm{pH}$-sensitive, the absorbance peak equivalent to each drug should be seen, as previously reported [16].

\section{Animal model}

We conducted a controlled comparative experimental study using 120 Syrian golden male hamsters (Mesocricetus auratus, 5 weeks old, weighing $80-110 \mathrm{~g}$ ). They were obtained from VACSERA, Cairo, Egypt. The animal study was approved by the Alexandria University review committee and the procedures followed are in accordance with institutional guidelines (IRB\#00010556-IORG0008839). The hamsters were weighed once per week throughout the whole period of the experiment. They were housed in show box cages (Technoplast, Italy) one per box under the same condition on a regular alternating lighting cycle (12:12 light: dark).

To establish an oral cancer model, we chemically induced OSCC by painting the left buccal pouch, only to facilitate eating by the other side, of the hamsters with 7, 12 dimethylbenz [a] anthracene carcinogen (DMBA, Sigma Aldrich, 57,976 Germany). We used hamster buccal pouch as our oral cancer model due to the similarities between its lining mucosa and the epithelium covering hard palate, tongue and gingiva of human oral cavity. Furthermore, multiple correspondence to human OSCC were found regarding morphology, molecular markers expression, and finally DNA mutations [18].

During the carcinogenesis phase, we used DMBA along with a carbamide peroxide as a promoter, 5 days per week (alternate days, 3 days for DMBA and 2 days for the promoter) [19]. We specifically used this promoter to decrease the induction period from 16 weeks to less than 12 weeks and obtaining a welldeveloped intraoral OSCC exophytic masses. This was done to minimize the handling procedures throughout the experiment with the animals and the carcinogen. Carcinogenesis was evaluated microscopically 4 weeks after induction by sacrificing cohorts of 2 hamsters every 2 weeks and evaluating lesions with $H \& E$ staining until well-established OSCCs were detected. Moreover, hamsters with tumor size greater than $2 \mathrm{~cm}$ in diameter were dropped from the study and euthanized before the predetermined time point ( 4 weeks).

\section{Treatment protocol}

After inducing visible oral exophytic polyps, the reminder hamsters $(n=104)$ were blindly randomized into 8 groups using computer generated list of random numbers ( $n=13$ hamster per group). Three groups were injected with the free forms of $5 \mathrm{Fu}, \mathrm{CPT}$ and FGFR1i with a dose of 12,2 , and $0.5 \mathrm{mg} / \mathrm{kg}$, respectively [20, 21]. Another 3 groups were similarly injected up to $150 \mu \mathrm{l}$ of the prepared functionalized AuNSs with the 3 drugs 5Fu-AuNSs, CPT-AuNSs, and FGFR1i-AuNSs equivalent to the administrated free dose of $5 \mathrm{Fu}, \mathrm{CPT}$ and FGFR1i $(12,2$, and $0.5 \mathrm{mg} / \mathrm{kg})$, respectively. Finally, 2 groups served as controls receiving saline and PEGRGD-AuNSs ( $150 \mu \mathrm{l}$ same as treatment dose) without any loaded drug. Each group received the designated treatment 3 times/week for a period of 1 week by an intraperitoneal (I.P.) injections under lightly sedation using ketamine hydrochloride [22]. All investigators were blinded throughout the whole experiment (During allocation concealment, outcome assessment and data analysis). The animal groups were known only by the animal care staff who administered the drugs. After treatment according to the planned protocol, animals were sacrificed by cervical decapitation under anesthetic 
conditions (Ketamin $30 \mathrm{mg} / \mathrm{kg}$, i.p.). Finally, any animal disposals were burned.

\section{Tumor volume reduction rate and survival analysis}

We measured tumor volume before and weekly after (be more specific) administration of the treatment. It was estimated by using the formula ( $\mathrm{D} \max \mathrm{X} \mathrm{D} \min ^{2} / 2$ ), where (D max) represents longer dimension and ( $\mathrm{D}$ min) represent shorter dimension. We performed sequential measurements over a period of 4 weeks to assess the tumor volume percentage change and we calculated the survival rate as days.

\section{Drug release and localization upon cellular uptake}

We tested the cellular uptake of AuNSs and subsequent release of the drugs using confocal laser scanning microscopy (CLSM, Leica TSC SPII/DMi 8). We used a previously published method to confirm drugs release [16]. Since $5 \mathrm{Fu}$ and $\mathrm{CPT}$ have fluorescence properties (emission spectrum: $405 \mathrm{~nm}$ and $490 \mathrm{~nm}$, respectively), we were able track their release and localization within cancer cells. Moreover, no nuclear fluorochrome was applied to tissue sections treated with 5Fu-AuNSs, CPTAuNSs, free $5 \mathrm{Fu}$ and $\mathrm{CPT}$ to avoid misinterpretation with the blue fluorescent for of CPT drug. But since EGFR1i does not possess fluorescence emission signal, we stained the targeted receptor using anti-FGFR1 antibody (Abcam, ab10646, USA) at a concentration of 1 : 100 , together with its compatible $2^{\text {ry }}$ antibody Alexa Fluor 488 (Abcam, ab150077, USA). Hoechst 33342 (Sigma Aldrich, 23,491-52-3, Germany) was used as a counterstain for DNA staining. After scarification procedures, we dissected the tumors biopsies and divided each one into 2 equal specimens. We selected the central part of tumoral tissue for all histologic evaluation. We examined 5 different histologic sections by 2 different pathologists for each slide on a magnification power $\times 63$. For autofluorescent cytotoxic drugs, we quantified the differences in the nuclear signals between free and conjugated counterparts using ImageJ software (version 1.52p).

\section{Histologic and immunohistochemical evaluation}

We stained the tumor tissue sections with H\&E stain to visualize the presence of oral carcinomas. To test the proliferative index of the tumor cells, we stained tissue sections using proliferating cell nuclear antigen (PCNA, Thermo scientific, MS-106-R7, USA) with a 1:50 dilution ratio of mouse monoclonal anti-PCNA antibody. We also used Ki67 to confirm the PCNA staining results (Ki67, Thermo scientific, \# MA5-14520, USA) with a 1: 200 dilution ratio of rabbit monoclonal anti-Ki67 antibody. We assessed tumor proliferation using different markers to capture all growing fraction in the tumor especially Ki67 which is steadily expressed throughout all cell cycle phases except G0 [23]. Immunohistochemical (IHC) staining was performed using the labeled streptavidin-biotin complex method (LSAB) [24] and the stained slides were captured by Motic image plus 2.0. PCNA and KI67 nuclear staining were measured by calculating intensity as mean area percent (MA\%) using ImageJ software (version 1.52p). Sections were blindly examined by 2 pathologists in randomly 5 selected microscopic fields at a magnification of $\times 400$.

\section{Cell cycle analysis}

We preserved a part of the excised oral tumors in complete RPMI tissue culture media (Sigma Aldrich, R8758, Germany). Following a modified standard protocol [25], we homogenized the fresh tissue specimens by thoroughly mincing with sharp surgical blades in cold RPMI medium on disposable petri dishes. The released cells were separated from remaining tissue by $100 \mu \mathrm{m}$ nylon cell strainers, centrifuged (2000 rpm, $20 \mathrm{~min})$, and incubated with $1 \mathrm{ml}$ trypsin enzyme for $20 \mathrm{~min}$. The cells were centrifuged again $(2000 \mathrm{rpm}, 5 \mathrm{~min})$ to remove the trypsin enzyme. Afterwards, 2 washes were done using FACS buffer (PBS+ BSA) followed by centrifugation for $5 \mathrm{~min}$ after each wash. Then, we fixed the cells using $70 \%$ ice cold ethanol while vortexing to prevent cell clumping and stored the cell suspensions at $-20^{\circ} \mathrm{C}$ until FACS analysis. Upon examination, the cell suspension was allowed to reach room temperature and centrifuged for $5 \mathrm{~min}$ to remove excess alcohol. This was followed by 2 washes using FACS buffer with centrifugation for 5 min after each wash. Further, sample purification was done by re-filtering the cell suspension using $100 \mu \mathrm{m}$ nylon cell strainers mesh. Finally, we added $100 \mu \mathrm{g} / \mathrm{ml}$ of propidium iodine PI (Sigma Aldrich, P4864, Germany) for DNA staining and $200 \mu \mathrm{g} / \mathrm{ml}$ RNAse (Sigma Aldrich, R5500, Germany) for RNA digestion at room temperature for $15 \mathrm{~min}$. We analyzed all the samples using a FACS Caliber (BD Biosciences, USA).

\section{Evaluation of the systemic adverse effects of different treatments}

We monitored the hamsters for signs of alopecia, diarrhea and weight loss throughout the treatment course. To investigate the impact of these nano-constructs on the hematopoietic system since this is one of the most affected organs after treatment, we collected blood samples from all the hamsters to assess possible myelosuppression. After administration of the final treatment dose, we sedated the hamsters to collect blood samples from the retro-orbital venous plexus [26]. The samples were taken at fixed intervals of 1,24 and $48 \mathrm{~h}, 1$ week and at time of euthanasia (4 weeks). We assessed the count of red blood cells (RBCs), white blood cells (WBCs), hemoglobin, and platelets. At necropsy, we 
examined the rest of the buccal pouch dissected from hamsters for any signs of drugs related effects. Moreover, we collected the liver and kidneys to histologically identify any damage to their normal architecture. The tissue specimens were fixed in 10\% neutral-buffered formalin solution and embedded in paraffin wax for $H \& E$ staining and examined with a light microscope.

\section{Data representation and statistical analysis}

Data analysis and graphs were produced using GraphPad Prism software (Prism 8, version 8). All values were expressed as mean \pm standard deviation (SD). Tumor volume change, IHC staining data, nuclear localization data were analyzed using one-way ANOVA test and further analysed using Dunnett's multiple comparison tests. Blood count was analyzed using two-way ANOVA test to include 2 factors of interest, time and treatment. Hamster survival curves were estimated by KaplanMeier method and analyzed by the Log-rank (Mantelcox) test. The level of statistical significance $(p<0.05)$ was indicated on plots with asterisks $\left(^{*}\right)$. We used model assumptions checking using the Shapiro-Wilk normality test and Levene's test for homogeneity of variance. The sample size calculation was based on the expected difference in the cell cycle counts between the group treated with $5 \mathrm{Fu}$ as free form against the conjugated form $=40 \%$, with precision of $10 \%$ using alpha error $=0.05$ with study power of $80 \%$. The sample size was calculated using G.STATA 11 Software. The total sample size was calculated as 112 hamsters then increased to reach 120 hamsters to compensate sample drop off (death as a complication of the cancer induction) [27].

\section{Results}

Using HBPC as our cancer model, we noticed a generalized increased potency of all the conjugated drugs compared with their free form with almost no off-targets side effects. Interestingly, we found that AuNSs selectively enhances the therapeutic effect of small molecule inhibitors such as compared with potent anticancer drugs such as $5 \mathrm{Fu}$ and $\mathrm{CPT}$.

\section{Characterization and functionalization of the synthesized AuNPs}

Synthesized AuNSs were characterized to verify their size, shape and mono-distribution. Using TEM, and the Nano-Zetasizer, we confirmed that the synthesized AuNSs were monodispersed spherical nanoparticles with a mean size of $27.1 \pm 2.73 \mathrm{~nm}$ (Fig. 1a). UV-Vis spectrometer showed a peak at maximum absorbance equal to $528 \pm 1 \mathrm{~nm}$, which is equivalent to an average size of $30 \mathrm{~nm}$. There was no change in the maximum absorbance of the nanoconjugates $(\sim 528 \mathrm{~nm})$ detected by the UV-spectrometer, indicating lack of aggregation with no significant change in size (Fig. 1b) [28].

To verify the conjugation process, we used the NanoZetasizer and UV-spectrometer to take measurements before and after loading each ligand. The changes in the surface charge of nanospheres, measured by the NanoZetasizer, reflected the docking status of the nanospheres. For example, bare AuNSs solution was strongly negative $(-24 \mathrm{mV})$, indicating a stable colloidal AuNPs solution with no possibility for subsequent aggregation [29]. Coating AuNSs with different ligands induced changes in zeta potential measurements as follows: -24

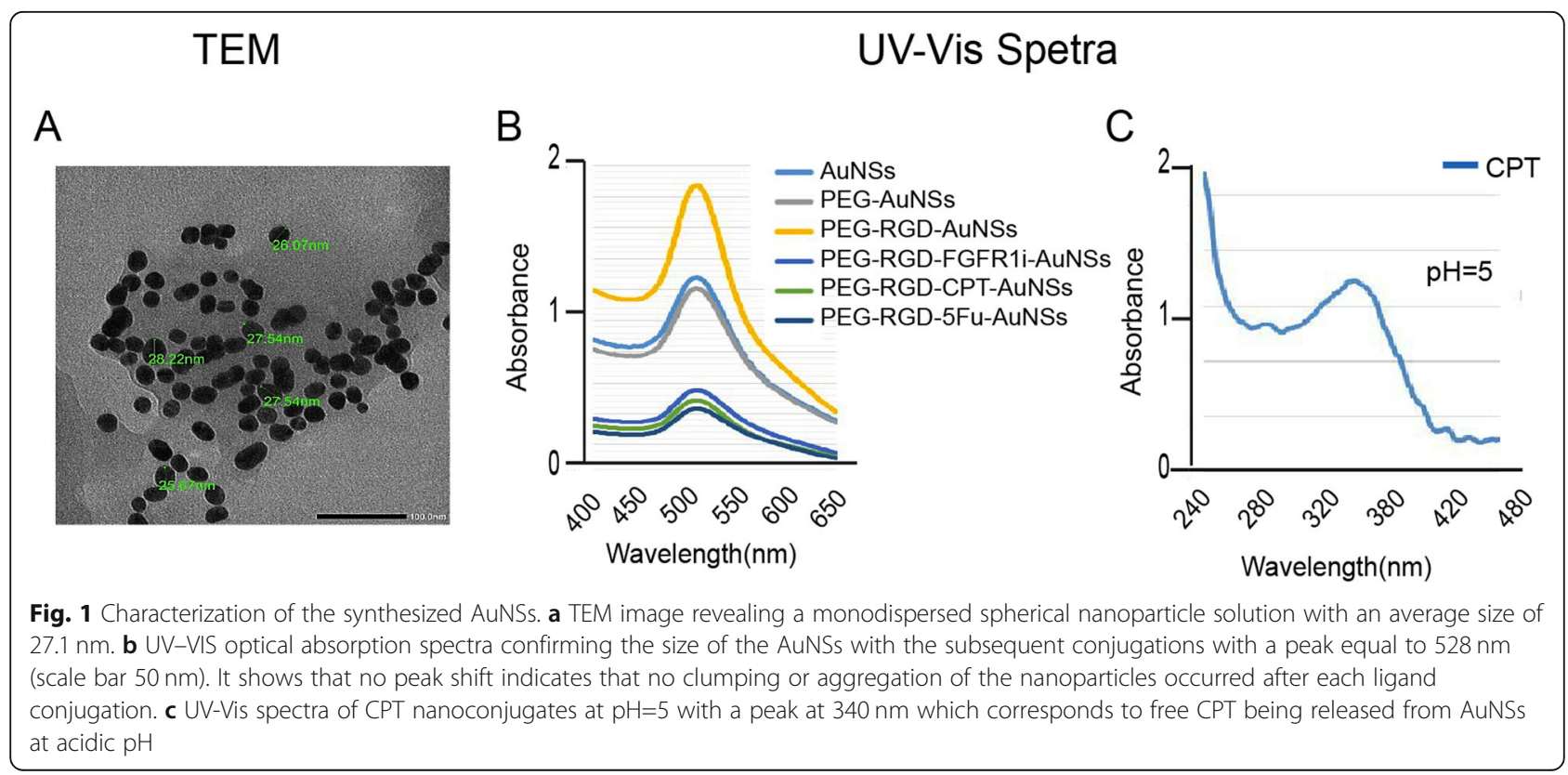


$\mathrm{mV}$ to $-26.6 \mathrm{mV}$ when adding PEG followed by -21.3 $\mathrm{mV}$ upon RGD conjugation. Finally, $-19.7 \mathrm{mV}$ was the zeta potential value of the AuNSs suspensions after adding $5 \mathrm{Fu}, \mathrm{CPT}$, or FGFR1i which was measured after conjugation and immediately before IP injection (Table 1). The change noted in the zeta potential values indicated a successful conjugation process [30]. We previously reported that AuNSs loaded with drugs release their cargo upon cellular uptake in the lysosomes due to the acidic $\mathrm{pH}(\mathrm{pH}=5)$ [29]. Accordingly, we wanted to confirm that the hydrazone bond used to conjugate AuNSs linkage in the synthesized nanoconjugates are $\mathrm{pH}$-sensitive. Therefore, we did an in vitro experiment in a test tube, where we added an acidic buffer to the nano-constructs. After centrifugation, we discarded the AuNSs pellet and measured the absorbance of the supernatant. After adding an acidic buffer to the nanoparticles solution, UV-VIS results showed peaks representing the drugs released in the acidic pH something. Figure 1c shows an example of an absorbance spectrum of the supernatant separated from CPT-AuNSs solution. Note the peak was located around $360 \mathrm{~nm}$, which is equivalent to the maximum absorbance of CPT as reported previously [31]. The UVVis results verified that acidic $\mathrm{pH}$ released the drugs from their nanocarriers.

\section{Tumor penetration and cellular uptake of the nanoconjugates}

We investigated tumor and cellular uptake, and delivery of different nano-constructs in comparison with their free forms. Our research group recently performed an extensive characterization to verify NPs uptake, in vitro, of a similar system but with Doxorubicin as the cytotoxic agent of choice [32]. Here in, we used the fluorescence properties of $\mathrm{CPT}$ and $5 \mathrm{Fu}$ to quantify the cellular uptake of the nanoconjugates in comparison to the free form. Based on a previously published principle, we used the selective quenching effect induced by the plasmonic field of AuNSs to track tumor penetration and cellular uptake in our OSCC animal model [29].

To study the extent of tumor penetration of FGFR1iAuNS, we stained the treated tumor tissue sections with anti-FGFR1 biomarker because FGFR1i molecules lack

Table 1 Zeta potential readings

\begin{tabular}{ll}
\hline AuNSs & Zeta potential $(\mathbf{m V})^{\mathbf{a}}$ \\
\hline AuNSs & -24.6 \\
PEG-AuNSs & -26.6 \\
RGD-PEG-AuNSs & -21.3 \\
5FU-AuNSs & -19.3 \\
CPT-AuNSs & -12.8 \\
FGFR1i-AuNSs & -6.47 \\
\hline
\end{tabular}

${ }_{\mathrm{a} V}$ stands for millivolts autofluorescence properties. This approach allowed us to trace the FGFR1i inhibitory effect as a function of its tumor penetration and selective targeting of cancer cells. Untreated tumor tissue sections showed a generalized and diffuse cytoplasmic reaction throughout the specimen, reflecting high expression levels of FGFR1 (Fig. 2ac). Tissue sections isolated from tumors treated with FGFR1i revealed a lesser extent of FGFR1 expression, mostly towards the periphery of the tumor (Fig. 2d-f). We noted complete loss of FGFR1 expression in tumors treated with FGFR1i-AuNSs, extracted from the center of the specimen; thus, indicating a high tumor penetration and enhanced drug delivery to cancer cells (Fig. 2gi).

Cytotoxic drugs such as $5 \mathrm{Fu}$ and CPT are commonly used to treat OSCC in vitro, in vivo, and in patients. They possess a fluorescence emission signal, which can be used to quantify the extent of their penetration in the tumor and their nuclear localization upon cellular delivery. Our data reveals that conjugating $5 \mathrm{Fu}$ and $\mathrm{CPT}$ to AuNSs significantly enhanced tumor cell uptake and more specifically nuclear localization by at least $25 \%$ compared with the free forms (Fig. 2k-s). Tumor specimens treated with 5Fu-AuNSs and CPT-AuNSs showed an intensified fluorescent signal located in the nuclei, which became less prominent towards the cell membranes of tumor cells as shown in (Fig. 2m, o, q, s). This can be explained by intra-nuclear drug accumulation after their release from AuNSs in the lysosomes. Meanwhile, the free forms of the drugs were able to passively penetrate the tumor tissue, compared with untreated tumor section, and accumulate in the plasma membrane of tumor cells showing much less colocalization in the nuclei (Fig. 2l, n, p, r). 5Fu and CPT along with their nanoconjugates revealed a significant intranuclear drugnanoconjugate accumulation compared to their free forms by a 2-fold increase for $5 \mathrm{Fu}$ and 3-fold for CPT. Although $5 \mathrm{Fu}$ and $\mathrm{CPT}$ free forms resulted in same fluorescent signal values, however, upon calculating the mean percentage of CPT-AuNSs and 5Fu-AuNSs nuclear localization, we discovered a significant increased fluorescent signalling for CPT-AuNSs as shown in (Fig. 2j) compared to $5 \mathrm{Fu}$-AuNSs.

\section{Cell cycle analysis}

After fluorescence imaging confirmed superior penetration and drug delivery in tumors treated with the nanoconjugates, the next critical milestone was looking into cell cycle progression anomalies. This is because targeted signaling pathways and proteins induce a direct impact on cell cycle progression, regardless of the upstream events leading to it.

Cell cycle analysis have shown that tumor cells isolated from animals treated with $5 \mathrm{Fu}$ or $\mathrm{CPT}$, whether in their 


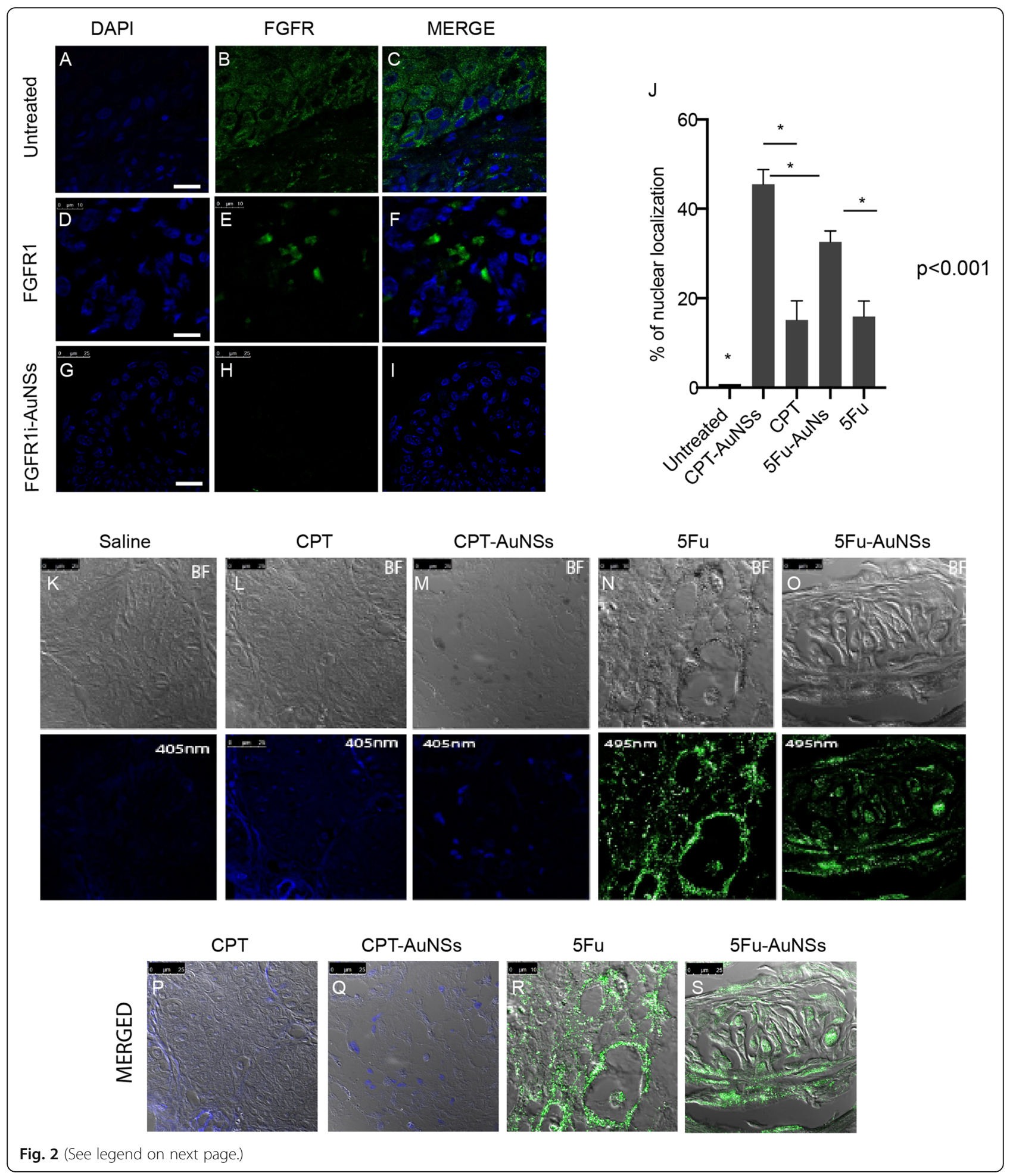




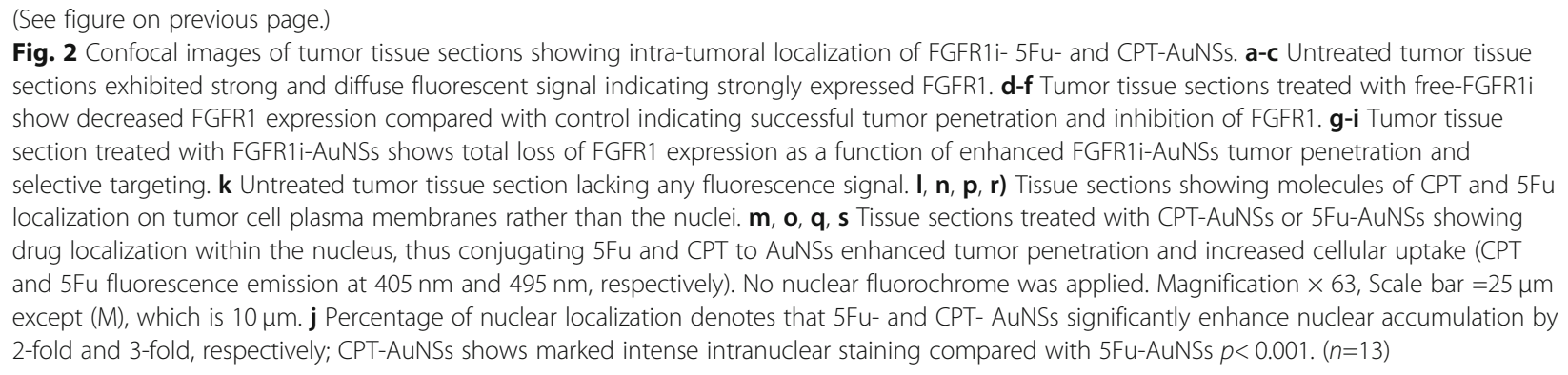

free form or conjugated to AuNSs, have similar distribution of cell cycle phases at a given time point after treatment. The cytotoxic drugs induced S-phase arrest $(40 \%$ of the cell population) with complete depletion of G2/ M. Tumor cells that were in G1 phase comprised around $60 \%$ of the total population (Fig. 3). Cancer cells isolated from tumors treated with free FGFR1i or its conjugated form also showed complete G2/M depletion, while maintaining the same percentage $(\sim 60 \%)$ of G1-phase cells as those treated with $5 \mathrm{Fu}$ and CPT drugs. Interestingly, $\sim 22 \%$ of tumor cells treated with FGFR1i-AuNSs were in subG1-phase, which is indicative of an activated cellular apoptosis and subsequently cell death (Fig. 3) [33].

\section{Cessation of tumor cells proliferation}

Our cell cycle analysis shows that the drugs conjugated to AuNSs had similar cell cycle phase distributions with the exception of FGFR1i-AuNSs which induced a $22 \%$ of the cancer cells to arrest in sub-G1(G0). Changes in the cell cycle phase distributions are induced by the drug's mechanism of action and that AuNSs are indeed vehicles. We then wanted to determine what happens once cell cycle progression is disturbed. Therefore, we used anti-PCNA and anti-Ki67 biomarkers to assess the proliferative activity and cell cycle progression of the tumor cells in different groups. PCNA is a nuclear nonhistone protein that is necessary for DNA synthesis, thus higher expression levels are noted during G1-S phase transition [34]. Ki67 protein expression levels peak at G2 and G2/ $M$ phase [35]. Tumor tissue sections showed numerous nests of malignant epithelial cells in fibrous tissue stroma. Each nest is peripherally lined with columnar basal cells, while the center is formed of polyhedral-like cells. Several nests showed central keratin pearls indicating that excised polyps are mostly moderate well differentiated OSCC.

Untreated tumors were comprised of malignant cell nests that showed positive PCNA and Ki67 immunoexpression. Cell nests showed diffuse positive nuclear PCNA immunoreaction, while Ki67 staining was only localized in the nuclei of the basal cells (Fig. 4a). PEGAuNSs treated tumor sections showed a humble negative impact on the proliferative rates of tumor cells (Fig.
$4 \mathrm{~b}, \mathrm{i}, \mathrm{j})$. Tumors treated with nanoconjugate drugs showed significantly less PCNA and Ki67 immunoreaction $(<20 \%$ of the total area occupied by tumor cells) compared with those treated with the free form of the drugs $(<30 \%)$, but both forms induced significant decrease in the proliferative capacity of the tumor cells compared with untreated tumors $(>70 \%$ of the total area occupied by tumor cells) (Fig. 4a-j). We found that CPT, 5Fu, and FGFR1i which have different mechanism of actions inhibited the proliferative activity of tumor cells in a similar rate (Fig. $4 \mathrm{i}, \mathrm{j})$.

\section{Impact of FGFR1i-, CPT-, and 5Fu-AuNSs injections on the developed HBPC}

By the end of the cancer induction phase, 10 hamsters with hepatosplenomegaly and ascites died as a complication related to ingestion of DMBA painting. Six hamsters were scarified, and buccal tissue biopsies were fixed and stained with $H \& E$ to evaluate the carcinogenesis. The remaining 104 hamsters developed polypoid OSCC tumor masses with an incident rate of $100 \%$ and tumor multiplicity of 1.27 tumors per hamster. Microscopically, the developed carcinomas were in the form of well, moderately and poorly differentiated types resembling human oral carcinomas with chronic inflammatory cell infiltrates in the supporting connective tissue.

To test the therapeutic efficiency of the nanoconstructs, we measured tumor volume in different animal groups over time (Fig. 5a-h). After 4 weeks of treatments, animals treated with FGFR1i-AuNSs yielded the highest reduction in tumor volume with a 2 -fold decrease $(-63.09 \%)$ compared with those injected by CPTAuNSs (-32.1\%). Animals treated with 5Fu-AuNSs showed a tumor reduction rate equal to $-43.4 \%$. There was no significant difference in tumor reduction rates induced by 5Fu- and FGFR1i- AuNSs ( $p>0.05$ ) (Fig. 5i).

Several factors affect an animal's life span during cancer treatment. Tumor burden and toxicities related to therapeutic administration are considered the most important factors [36]. We measured survival rates across animal groups to assess the impact of the nanoconjugates versus free drugs on survival. The control group receiving saline showed an average survival of 12.4 days 


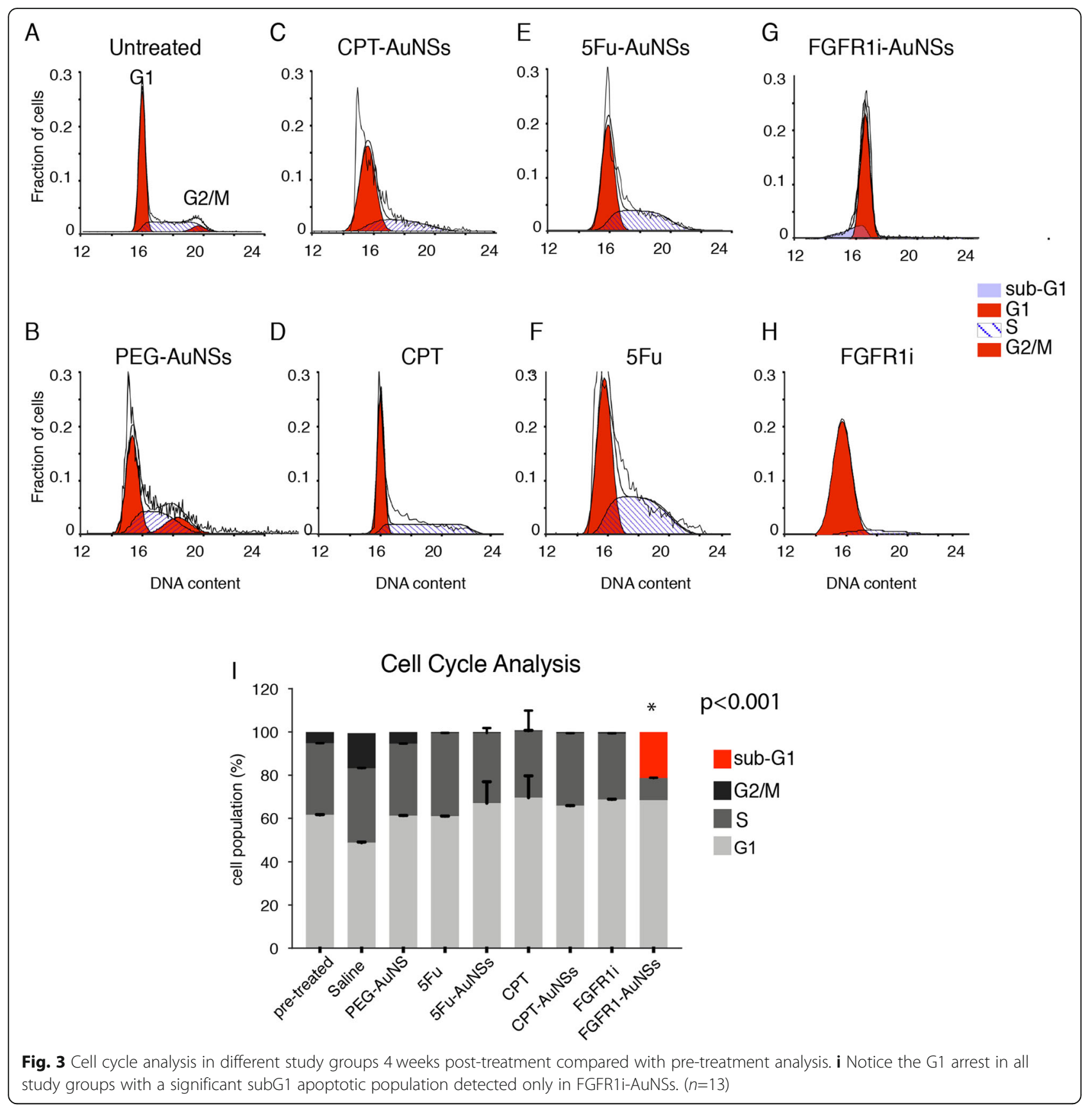

after the final dose. Similarly, animals treated with free FGFR1i showed poor survival rate (13.5 days). We noted that the free forms of CPT, 5Fu, and PEG-AuNSs enhanced the survival rates reaching 21and 24 days post treatment. This was significantly higher than control $(p<0.001)$. Conjugating AuNSs with FGFR1i, 5Fu, and CPT significantly enhanced survival rates to more than 27 days post treatment. Notably, the difference in life span among the 3 nanoconjugates was not statistically significant (Fig. 5j).

\section{Off-target systemic effects}

In the development of novel pharmacological agents, tolerability and therapeutic efficacy are the two most critical factors. After evaluating the therapeutic efficacy of FGFR1i-AuNSs, we examined the treated hamsters for signs of damaging side effects. At first, we monitored different parameters, including weight loss, diarrhea, and alopecia throughout the study period. We did not observe any signs of toxicity after administration of FGFR1i- 5Fu- or CPT-AuNSs. Nine out of the 13 hamsters 


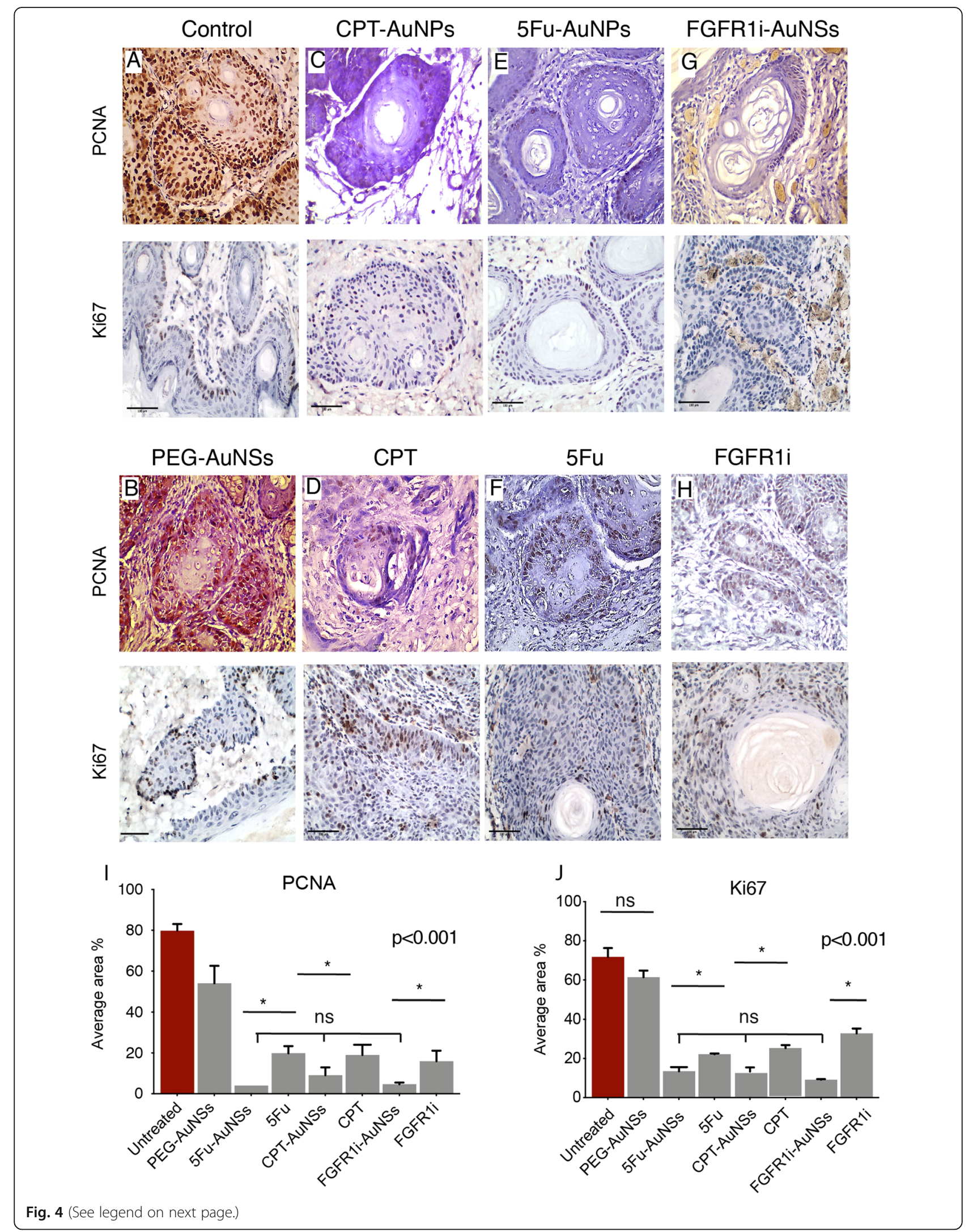


(See figure on previous page.)

Fig. 4 Immunohistochemical expression of PCNA and Ki67 in tumor tissue sections isolated from treated animals. a, b Untreated tumors cells expressing PCNA and Ki67 proteins indicating their cycling status, while PEG-AuNSs seems to induce a minimal inhibition to PCNA and Ki67 proteins. c-h FGFR1 i- CPT- and 5Fu- AuNSs induced a significant inhibition to PCNA and Ki67 activity compared with the free form. $\mathbf{i}$, $\mathbf{j}$ Bar chart plots of the average tissue section area showing positive immunoreaction for both PCNA and Ki67 normalized to the total area. The drugs and their corresponding nanoconjugates resulted in significant lack of proliferation of the tumor cells compared with untreated and PEG-AuNSs treated cells. There was no significance difference between the inhibitory effect induced by CPT, 5Fu and EGFRi (denoted by ns). Also, the same drug nanoconjugates appear to induce equivalent rates of cellular arrest. PCNA and Ki67 immunoreactions were significantly lower in tumor cells treated with FGFR1i- CPT- and 5Fu- AuNSs compared with the free forms. Findings were considered statistically significant when $p<0.001$ and are denoted by asterisks. Scale bars $=100 \mathrm{um}(n=13)$

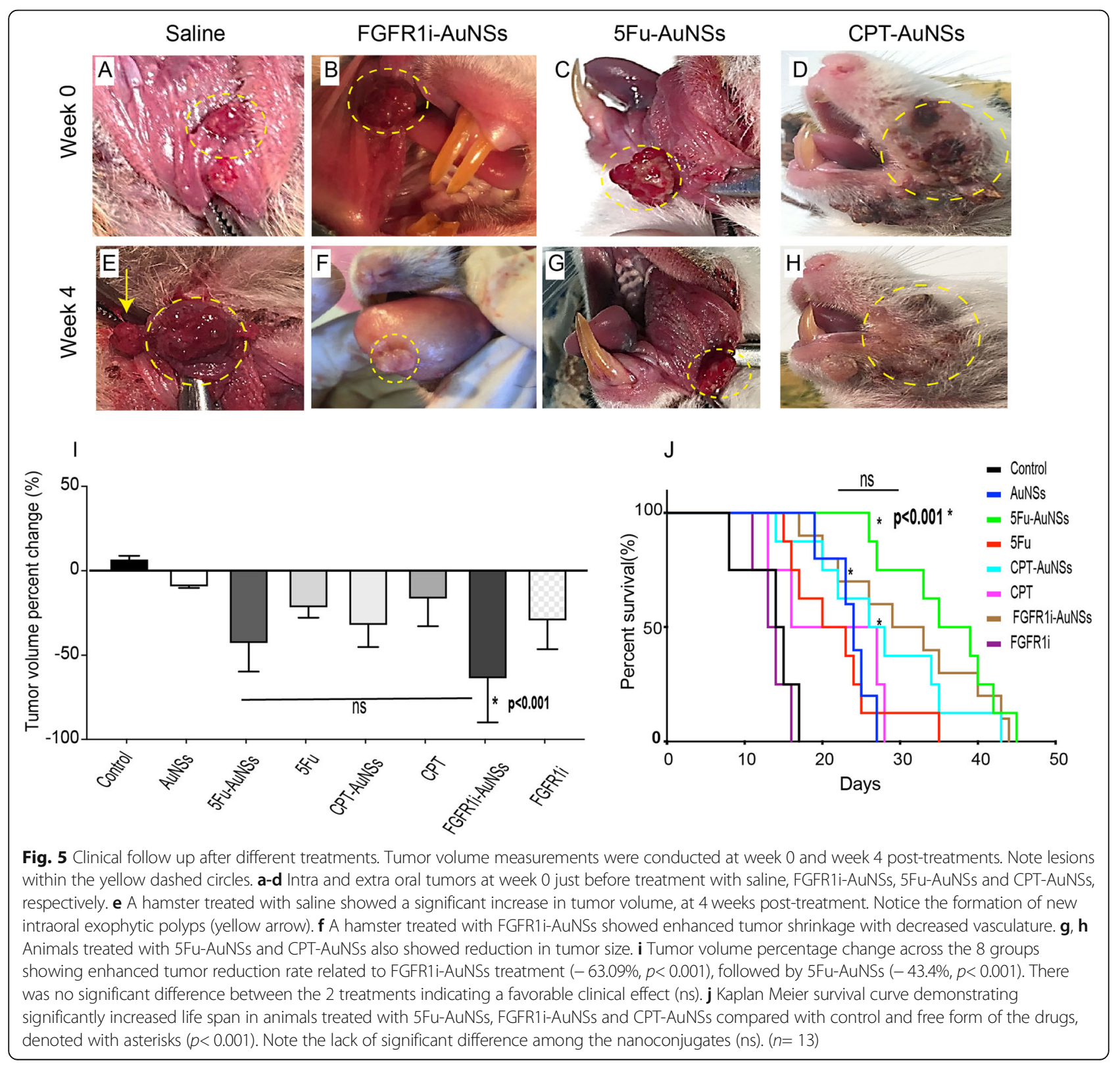


treated with CPT showed partial alopecia (Fig. 6a). We examined the rest of the HBPC aside from the tumor mass which showed a normal thin corrugated lining epithelium with some focal thinking as a reaction to the DMBA application. Microscopic examination of liver and renal tissue isolated from animals treated with the nanoconjugates showed normal liver and renal tissue architecture. We did not note any signs of toxicity nor AuNSs precipitation in these organs. (Fig. 6b). Areas of glomerular shrinkage were seen in kidney sections after treatment with CPT and 5Fu. These hamsters also showed hydropic degeneration of the hepatocytes with focal necrosis in the central vein zone in liver sections (Fig. 6c-e).

Finally, we assessed the complete blood count through a series of drawn blood samples taken over time to monitor RBC, WBC and platelet counts as a proxy of the animal's overall health (Fig. 6f, g, i). Multiple comparison tests between complete blood (WBCs, RBCs, platelets, and hemoglobin) counts in our study groups revealed no significance difference between untreated and PEG-AuNSs treated animals which falls within the normal range. This was true across all the time intervals (Fig. 6f-i). Animals treated with drug nanoconjugates did not show any significant change in their WBCs, RBCs, and hemoglobin counts at $1 \mathrm{~h}, 24 \mathrm{~h}, 48 \mathrm{~h}, 1$ week, and 4 weeks post-treatment $(p>0.999)$. Regarding platelets count (Fig. 6f), CPT- and 5Fu- AuNSs caused thrombocytopenia one week after treatment. While FGFR1i-AuNSs induced a significant thrombocytosis early in the treatment course at the 1-h time point, which was spontaneously corrected afterwards. Interestingly, free FGFR1i induced significant thrombocytosis persisted until the last time point ( 4 weeks post-treatment) $(p<0.01)$. For $\mathrm{RBCs}$ and WBCs values, there were no significant differences between blood count changes induced by the drug nanoconjugates throughout the whole period ( $p>0.999$ ) (Fig. 6g, h). However, FGFR1i-, CPT-, and 5Fu-AuNSs induced comparable blood cell readings at all time points. Cytotoxic drugs, free forms of 5Fu and CPT induced a generalized pancytopenia after 1 week of injections. Meanwhile, the unconjugated FGFR1i induced significant anemia starting from the 48-h point interval to 4 weeks post-treatment (Fig. 6i).

\section{Discussion}

It is widely accepted that AuNSs play a crucial role in improving the therapeutic efficiency of anticancer drugs through active targeting and enhanced cellular uptake, thus drug delivery [37]. Studies using single-nanoconjugate system concluded that cellular response and clinical outcome is strictly tailored by the mode of action and pharmacokinetics of that drug conjugated to the AuNSs [38]. Given that studies leading to such conclusions used single nanoconjugates, one could speculate that ruling out the therapeutic potential of AuNSs requires testing different drugs conjugated to similar sized and shaped AuNSs using the same chemical linker. We conducted this study to compare the cellular responses and in vivo clinical outcomes when treating $\mathrm{HBPC}$ with conjugated anticancer agents with different mode of actions (CPT-, 5Fu-, FGFR1i- nanoconjugates). Drugs were loaded on the surface of similar sized and shaped AuNPs using the same conjugation techniques as well as the same surface coverage ratio. The nanoconjugates were found to take the same route, starting from being injected to the animal's vascular system until they induced tumor shrinkage, thereby enhancing survival rate. Upon intraperitoneal injection of AuNSs, the covalently bonded PEG molecules prevented opsonization and subsequent elimination from the blood stream [6]. Once the initial obstacle is bypassed, RGD peptide, also covalently bonded to the AuNSs, actively targets oral cancer cells but not the normal mucosa. RGD targets $\alpha v \beta 6$ surface integrins expressed on oral cancer cells [7]. This precise navigation system has proven to be more favorable than PEG-AuNSs alone as previously published by our group [2].

Due to tumor's acidic $\mathrm{pH}$ as well as lysosomal structures, drugs were released via the breakage of $\mathrm{pH}$ sensitive hydrazine bond and subsequently bind to their intracellular targets. Our findings show that AuNSs enhanced tumor penetration and cellular uptake of the drugs compared with their free forms. As expected, AuNSs are the key players in determining cellular uptake rates and not the drugs' affinity to their targets. This was confirmed by the lack of FGFR1 expression in tumor tissue sections treated with the FGFR1i-AuNSs. Similarly, $5 \mathrm{Fu}$ - and CPT- molecules were released by lysosomal acidic $\mathrm{pH}$ and consequently localized in the nucleus. This was confirmed by their autofluorescence colocalization with the nucleus, following a previously published concept [39]. Counterintuitively, tumor volumes data suggests that FGFR1i-AuNSs induced higher tumor reduction rates than potent $5 \mathrm{Fu}$ - and $\mathrm{CPT}$ nanoconjugates. Meanwhile, in normal keratinocytes, FGFR1 is located on the cell surface, however, as reported by Nguyen et al in oral squamous cell carcinoma, FGFR1 is translocated to the cytoplasm, nuclear membrane and nucleus [12]. He observed that in well diff SCC, FGFR1 is expressed in the cytoplasm however the nucleus showed strong FGFR1 expression in poorly diff SCC. His findings confirm that FGFR1i is targeting cytoplasmic and/or nuclear FGFR1 and not the surface receptor in OSCC. Moreover, our confocal results confirmed Nguyen's findings since FGFR1 fluorescence activity was noted mainly in the cytoplasm. This confirms that RGD was the sole exclude any help from a surface receptor and depending solely on RGD as a targeting moiety like in 5Fu-AuNS and CPT-AuNS treated groups. This suggests that despite being a small molecule inhibitor rather than a 

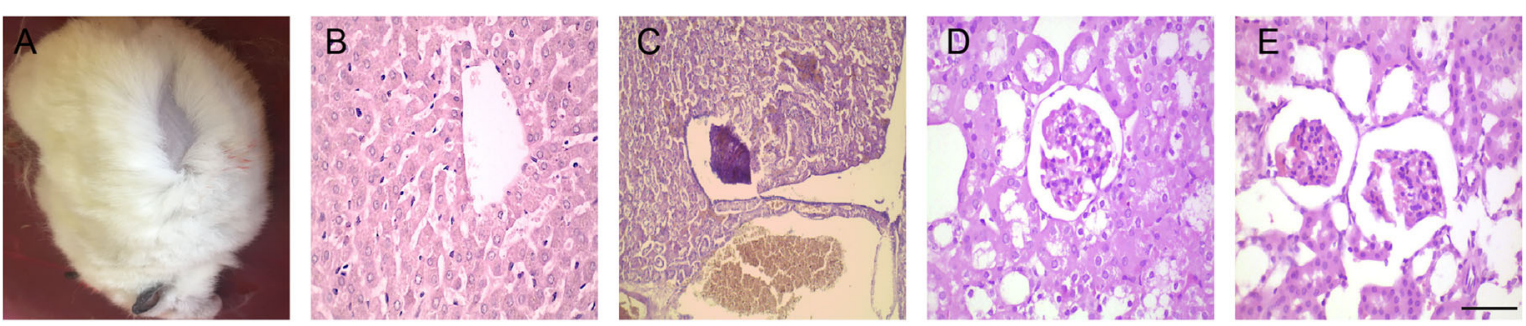

F

WBCs average normal value $=10-15 \times 10^{3} / \mathrm{mm}^{3}$

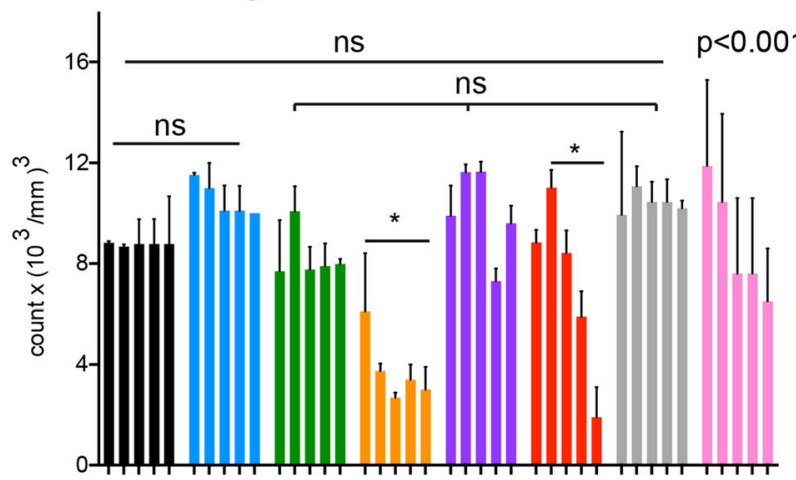

Untreated

— PEG-AuNSS

5Fu-AuNSs

$5 \mathrm{Fu}$

Hemoglobin

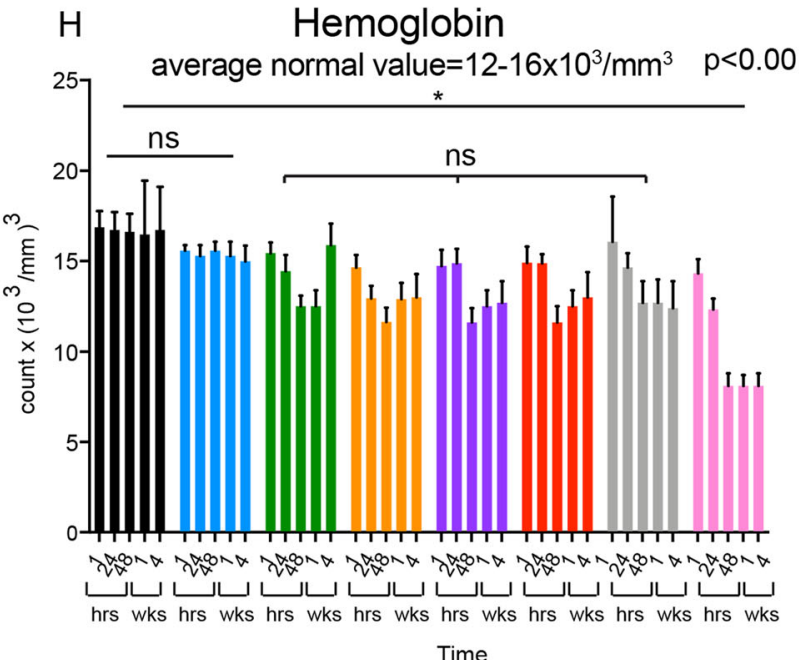

G

Platelets

average normal value $=400-600 \times 10 / \mathrm{mm}^{3}$

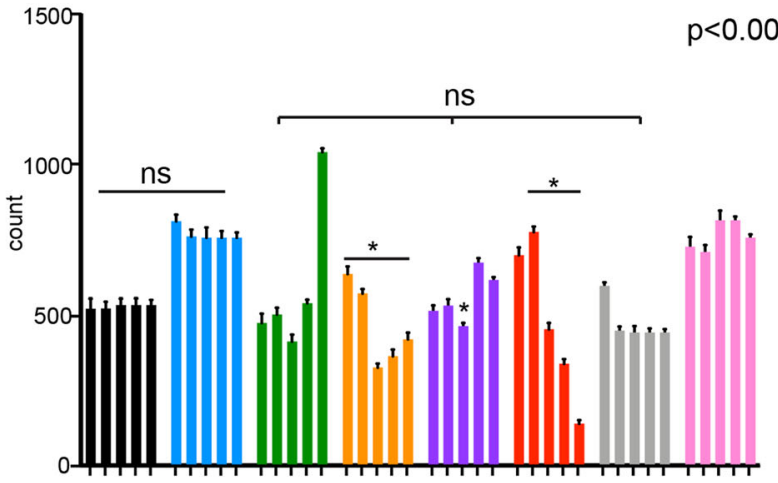

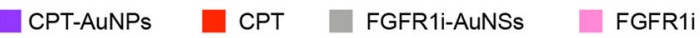

Fig. 6 Off target different systemic effects. We conducted clinical, histopathologic and hemopoietic assessment 4 weeks post-treatment. a A hamster treated with CPT showing partial alopecia. b Normal liver section extracted from 5Fu-AuNSs conjugated group showing normal hepatocytes and liver parenchyma. The same images were obtained from the other 2 nanoconstructs. c Liver section showing focal necrosis near the portal vein obtained for both free cytotoxic drugs CPT and 5Fu. $\mathbf{d}$, e Areas of glomerular shrinkage in hamsters receiving CPT and 5Fu. $\mathbf{f}$ Platelet count for the 8 groups across all time points; no significant difference was noted between the 3 nanoconjugates groups (ns) with only one exception seen for CPT-AuNSs at $48 \mathrm{~h}$. A significant decrease in the platelets count was seen in both free 5Fu and CPT denoted with asterisks $(p<0.001)$. g RBCs count showing no significant difference between the 3 nanoconjugates groups (ns) $(p<0.001)$. $\mathbf{h}$ WBCs values also show no significant difference between the 3 nanoconjugates groups (ns) $(p<0.001)$, while a significant fluctuation was seen for WBCs count in both cytotoxic drugs denoted with asterisks $(p<0.001)$. i For haemoglobin, no significant difference was found across all groups except the unconjugated form of FGFR1i denoted with asterisks $(p<0.001)$. $(n=13)$ 
potent chemotherapeutic drug, FGFR1i induced the most favorable tumor suppression results once conjugated to AuNPs. Thus, AuNPs play a significant role in magnifying the inhibitory effect of a conjugated molecule rather than being a vehicle.

Given the fact that CPT and 5Fu localize in the nuclei, we assumed that uploading equal number of moieties to the same sized AuNPs will result in equal nuclear uptake. Quantifying 5Fu- and CPT-nuclear uptake in tumor cells show a significant increase in the nuclear localization of CPT compared with $5 \mathrm{Fu}$ despite comprising equal surface coverage of AuNPs (55\%). However, this is not an indication of an enhanced CPT nuclear uptake, but we speculate that the autofluorescence of $5 \mathrm{Fu}$ complex is especially true in the non-catabolic form. Once $5 \mathrm{Fu}$ molecule is converted to its active metabolites, they lose the autofluorescence signals giving a false impression of decreased nuclear uptake.

Irrelevant of their mode of action, anti-cancer agents halt cell cycle progression inducing tumor cells to arrest and subsequently trigger cell death pathways. In our work, we were only interested in the downstream effects of the nanoconjugates on the cell cycle machinery and not the cell death kinetics. Flow cytometry and cell cycle data shows that $5 \mathrm{Fu}$ - and $\mathrm{CPT}$ - induced a similar ratio of S-phase cell cycle arrest as nanoconjugates and in their free forms. CPT and 5Fu inhibit topoisomerase I and thymidylate synthase activities, respectively during DNA replication. There was no additional effect of AuNSs on the cell cycle indicating that their primary role is to deliver drugs to their designated destination at least when bound to drugs such as CPT and 5Fu [2]. Tumor cells treated with free or conjugated FGFR1i molecules exhibited a significant increase in the population of cells arrested in G1-phase compared with saline treated cells. This is due to the FGFR1i mode of action which inhibits MAPK pathway, thus arresting tumor cells in early G1-phase. Interestingly, FGFR1i-AuNSs induced significant sub-G1 cell population indicative of cellular apoptosis. This is likely due to the enhanced potency of the inhibitor in its conjugated form $[2,40]$. However, further studies are required to validate and understand the apoptotic effect triggered by FGFR1iAuNSs on tumor cells. Cell cycle analysis data indicate that potent cytotoxic drugs similar to $\mathrm{CPT}$ and $5 \mathrm{Fu}$ efficiently induce cell cycle arrest with/without being conjugated to AuNSs. On the other hand, conjugating AuNSs with small molecule inhibitors such as FGFR1i significantly enhance their effect on cell cycle progression compared with their free forms [2].

While the variability in cell cycle arrest patterns induced by $5 \mathrm{Fu}$-, CPT- and FGFR1i- AuNSs was expected, we wondered whether it would have similar functional impact on the proliferative activity/rates of tumor cells.
To answer this question, we measured the proliferative activity of tumor cells by staining tumor tissue sections isolated from different animal groups with anti- Ki67 and anti-PCNA markers. To our surprise, there was no significant difference in the proliferation rate of tumor cells treated with CPT-, 5Fu- and FGFR1i- AuNSs. Cell cycle arrest in S- or G1- phase induced similar cessation of proliferation rates [41]. However, drug nanoconjugates significantly halted tumor cells proliferation compared with the free forms of the drugs. This suggests that the enhanced cellular uptake and drug delivery by the AuNSs are more crucial than the drug's mode of action in ceasing the proliferation of cancer cells [8]. Despite the fact that tumor cells primarily form tumor tissue, it would be naïve to expect that tumor cell growth necessarily reflects tumor growth rate [42]. Tumor growth rate is suggested to be an outcome of complex interactions between tumor cells and their microenvironment, including fibroblasts, and blood vessels. Despite conferring similar proliferative rates, FGFR1i-AuNSs induced the highest tumor reduction rates $(-64 \%)$ followed by $5 \mathrm{Fu}-\mathrm{AuNSs}(\sim-45 \%)$. CPTAuNSs induced significantly lower tumor reduction rates compared with the 5Fu- and FGFR1i- AuNSs despite showing similar proliferation activity on the tumor cell level, as confirmed by the IHC data. This can be explained by the non-autonomous cellular effects induced by FGFR1i [43].

Off-target side effects of anti-cancer agents such as $\mathrm{CPT}, 5 \mathrm{Fu}$, and FGFR1i are well discussed in the literature focusing mainly on hemopoietic stem cell senescence, elevated liver and renal function tests, and alopecia [14, 44-46]. Our findings confirm that conjugating anticancer drugs to AuNSs significantly minimized the deleterious impact of otherwise free drugs molecules on the bone marrow. FGFR1i-AuNSs showed a slight thrombocytosis only at $1 \mathrm{~h}$ which was spontaneously corrected afterwards. While $5 \mathrm{Fu}$ - and CPTAuNSs showed minimal thrombocytopenia $48 \mathrm{~h}$ after treatment, we considered that minor changes in the blood parameter counts are due to gradual increase in the blood $\mathrm{pH}$ throughout the carcinogenesis process leading to dissociated to $\mathrm{PH}$-sensitive linker between the NSs and different drugs prior reaching the target area [47].

\section{Conclusions}

In conclusion, despite having different modes of action, CPT-, 5Fu-, FGFR1i- nanoconjugates seemed to differently regulate cell cycle response at the cellular level. Such variability in the cell cycle response did not have any significant impact on the overall clinical impact. Our data indicates that the cellular biological events do not predict the outcome seen in our in vivo model. 
Furthermore, our results suggest that AuNSs selectively enhances the therapeutic effect of small molecule inhibitors such as FGFR1i than potent anticancer drugs. These findings suggest that AuNSs play a bigger role than being drug vehicles. Future studies are required to better understand the underlying mechanism.

\section{Abbreviations}

AuNPs: Gold nanoparticles; AuNSs: Gold nanospheres; 5Fu: 5-Fluorouracil; CPT: Camptothecin; FGFR1i: Fibroblastic growth factor receptor 1; PCNA: Proliferating cell nuclear antigen; IHC: Immunohistochemistry; PEG: Polyethylene glycol; RGD: Arginyl-glycyl-aspartic acid (Arg-Gly-Asp); MAPK: Mitogen-activated protein kinase; HBPC: Hamster buccal pouch carcinoma; OSCC: Oral squamous cell carcinoma; DMBA: 7, 12 dimethylbenz [a] anthracene carcinogen; Hr: Hour

\section{Acknowledgments}

We would like to thank Dr. Mohamed El Kady and Dr. Ashraf Awad in Center of Excellence for Research in Regenerative Medicine and Its Application (CERRMA) in Faculty of Medicine, Alexandria University (STDF funded research center) for their efforts and support. We would like to thank Dr. Ahmed Elzoghby in the faculty of pharmacy at Alexandria University and director of the Cancer Nano-lab. Finally, the authors thank the NIH Fellows Editorial Board for editorial assistance.

\section{Authors' contributions}

HA: Conceptualization, Methodology, Validation, Data curation, investigation, Resources, Writing- Original draft preparation, Visualization. ZD and SE: Supervision. GM: Validation, Resources, Data curation, Supervision. HD: Methodology, investigation, Resources, Data curation. MA: Conceptualization, Formal analysis, Data curation, Writing- Reviewing and Editing, Supervision, Project administration. All authors have read and approved this manuscript.

\section{Funding}

There was no funding subjected to the research reported in this manuscript. The animal model and some of the chemical used in the work only were gifts from the Alexandria University Research Fund Program (ALEX REP), project code (HLTH-13). Open Access funding provided by the National Institutes of Health (NIH).

\section{Availability of data and materials}

All data included in this current study are available from the corresponding author upon request.

\section{Ethics approval and consent to participate}

The animal study was approved by the Alexandria University review committee and the procedures followed are in accordance with institutional guidelines (IRB\#00010556-IORG0008839).

\section{Consent for publication}

Not applicable.

\section{Competing interests}

The authors declare that they have no competing interests.

\section{Author details}

'Oral Pathology Department, Faculty of Dentistry, Alexandria University, Champilion Street, Azarita, Alexandria, Egypt. ${ }^{2}$ Histology and Cell Biology Department, Faculty of Medicine, Alexandria University, Alexandria, Egypt. ${ }^{3}$ Center of Excellence for Research in Regenerative Medicine and Its Application (CERRMA), Faculty of Medicine, Alexandria University, Alexandria, Egypt. ${ }^{4}$ Clinical Pathology Department, Faculty of Medicine, Alexandria University, Alexandria, Egypt. ${ }^{5}$ Laboratory of Cancer Biology and Genetics, Center for Cancer Research, National Cancer Institute, 37 Covent Dr., Room 4054, Bethesda, MD 20892, USA.
Received: 4 August 2020 Accepted: 27 January 2021

Published online: 17 February 2021

\section{References}

1. Davis ME. Nanoparticle delivery platform for solid tumors. In: Proceedings of the ASCO annual meeting 2014, Chicago, IL, USA, 30 may-3 June; 2014.

2. Afifi MM, Austin LA, Mackey MA, El-Sayed MA. XAV939: from a small inhibitor to a potent drug bioconjugate when delivered by gold nanoparticles. Bioconjug Chem. 2014;25(2):207-15.

3. Mackey MA, El-Sayed MA. Chemosensitization of cancer cells via gold nanoparticle-induced cell cycle regulation. Photochem Photobiol. 2014; 90(2):306-12.

4. Afifi MM, El Sheikh SM, Abdelsalam MM, Ramadan H, Omar TA, El Tantawi $M$, et al. Therapeutic efficacy of plasmonic photothermal nanoparticles in hamster buccal pouch carcinoma. Oral Surg Oral Med Oral Pathol Oral Radiol. 2013;115(6):743-51.

5. Ketabat F, Pundir M, Mohabatpour F, Lobanova L, Koutsopoulos S, Hadjiiski $L$, et al. Controlled drug delivery Systems for Oral Cancer Treatment-Current Status and Future Perspectives. Pharmaceutics. 2019;11(7):302.

6. Janát-Amsbury MM, Ray A, Peterson CM, Ghandehari H. Geometry and surface characteristics of gold nanoparticles influence their biodistribution and uptake by macrophages. Eur J Pharm Biopharm. 2011;77(3):417-23.

7. Tamkun JW, DeSimone DW, Fonda D, Patel RS, Buck C, Horwitz AF, et al. Structure of integrin, a glycoprotein involved in the transmembrane linkage between fibronectin and actin. Cell. 1986;46(2):271-82.

8. Rees P, Wills JW, Brown MR, Barnes CM, Summers HD. The origin of heterogeneous nanoparticle uptake by cells. Nat Commun. 2019;10(1): 2341.41.

9. Longley D, Harkin D, Johnston P. 5-fluorouracil: mechanisms of action and clinical strategies. Nat Rev Cancer. 2003;3:330-8.

10. Liu LF, Desai SD, Li TK, Mao Y, Sun M, Sim SP. Mechanism of action of camptothecin. Ann N Y Acad Sci. 2000:922:1-10.

11. Glimelius B, Garmo H, Berglund Å, Fredriksson LA, Berglund M, Kohnke H, et al. Prediction of irinotecan and 5-fluorouracil toxicity and response in patients with advanced colorectal cancer. Pharm J. 2010;11:61.

12. Nguyen PT, Tsunematsu T, Yanagisawa S, Kudo Y, Miyauchi M, Kamata N, et al. The FGFR1 inhibitor PD173074 induces mesenchymal-epithelial transition through the transcription factor AP-1. Br J Cancer. 2013;109(8): 2248-58.

13. Ye T, Wei X, Yin T, Xia Y, Li D, Shao B, et al. Inhibition of FGFR signaling by PD173074 improves antitumor immunity and impairs breast cancer metastasis. Breast Cancer Res Treat. 2014;143(3):435-46.

14. Brown AP, Courtney CL, King LM, Groom SC, Graziano MJ. Cartilage dysplasia and tissue mineralization in the rat following administration of a FGF receptor tyrosine kinase inhibitor. Toxicol Pathol. 2005;33(4):449-55.

15. Ghosh D, Sarkar D, Girigoswami A, Chattopadhyay N. A fully standardized method of synthesis of gold nanoparticles of desired dimension in the range $15 \mathrm{~nm}-60 \mathrm{~nm}$. J Nanosci Nanotechnol. 2011;11(2):1141-6.

16. Kang B, Afifi MM, Austin LA, El-Sayed MA. Exploiting the nanoparticle plasmon effect: observing drug delivery dynamics in single cells via Raman/ fluorescence imaging spectroscopy. ACS Nano. 2013;7(8):7420-7.

17. Bailly A, Correard F, Popov A, Tselikov G, Chaspoul F, Appay R, et al. In vivo evaluation of safety, biodistribution and pharmacokinetics of lasersynthesized gold nanoparticles. Sci Rep. 2019. https://doi.org/10.1038/ s41598-019-48748-3

18. Nagini S, Kowshik J. The hamster Buccal pouch model of Oral carcinogenesis. Methods Mol Biol. 2016;1422:341-50.

19. Faccin Bampi V, Ferreira Vilela W, Vilela Goncalves R, Tavares Rheingantz MG Minello LF, Braga da Silva JL, et al. The promoting effect of carbamide peroxide teeth bleaching gel in a preclinical model of head and neck cancer in hamster buccal pouch. Clin Exp Otorhinolaryngol. 2014;7(3):210-5.

20. Pardo OE, Latigo J, Jeffery RE, Nye E, Poulsom R, Spencer-Dene B, et al. The fibroblast growth factor receptor inhibitor PD173074 blocks small cell lung cancer growth in vitro and in vivo. Cancer Res. 2009;69(22):8645-51.

21. Householder KT, DiPerna DM, Chung EP, Wohlleb GM, Dhruv HD, Berens ME, et al. Intravenous delivery of camptothecin-loaded PLGA nanoparticles for the treatment of intracranial glioma. Int J Pharm. 2015;479(2):374-80.

22. Nelson JL, Roeder BL, Carmen JC, Roloff F, Pitt WG. Ultrasonically activated chemotherapeutic drug delivery in a rat model. Cancer Res. 2002;62(24):7280-3. 
23. Birajdar SS, Radhika M, Paremala K, Sudhakara M, Soumya M, Gadivan M. Expression of Ki-67 in normal oral epithelium, leukoplakic oral epithelium and oral squamous cell carcinoma. J Oral Maxillofac Pathol. 2014;18(2):169-76.

24. Bratthauer GL. The avidin-biotin complex (ABC) method and other avidinbiotin binding methods. Methods Mol Biol. 2010;588:257-70.

25. Ensley JF, Maciorowski Z, Pietraszkiewicz H, Klemic G, KuKuruga M, Sapareto $\mathrm{S}$, et al. Solid tumor preparation for flow cytometry using a standard murine model. Cytometry. 1987;8(5):479-87.

26. Parasuraman S, Raveendran R, Kesavan R. Blood sample collection in small laboratory animals. J Pharmacol Pharmacother. 2010;1(2):87-93.

27. Daniel W. Biostatistics. A foundation for analysis in the health science. 6th ed. NY: John Wiley and sons, Inc; 1995.

28. Amendola V, Meneghetti M. Size evaluation of gold nanoparticles by UV -Vis spectroscopy. J Phys Chem C. 2009;113(11):4277-85 2009/03/19.

29. Zhang XD, Wu D, Shen X, Liu PX, Yang N, Zhao B, et al. Size-dependent in vivo toxicity of PEG-coated gold nanoparticles. Int J Nanomedicine. 2011; 6:2071-81.

30. Sun L, Zhang Z, Wang S, Zhang J, Li H, Ren L, et al. Effect of pH on the interaction of gold nanoparticles with DNA and application in the detection of human p53 gene mutation. Nanoscale Res Lett. 2008; 4(3):216-20.

31. Dvoranováa D, Bobeničováa M, Šoralováab S, Breza M. On UV-Vis spectra and structure of the anticancer drug camptothecin in solutions. Chem Phys Lett. 2013;580:141-4.

32. Essawy MM, El-Sheikh SM, Raslan HS, Ramadan HS, Kang B, Talaat IM, et al. Function of gold nanoparticles in oral cancer beyond drug delivery: implications in cell apoptosis. Oral Dis. 2020. https://doi.org/10. 1111/odi.13551.

33. Fujii S, Okinaga T, Ariyoshi W, et al. Mechanisms of $\mathrm{G} 1$ cell cycle arrest and apoptosis in myeloma cells induced by hybrid-compound histone deacetylase inhibitor. Biochem Biophys Res Commun. 2013; 434(3):413-20.

34. Strzalka W, Ziemienowicz A. Proliferating cell nuclear antigen (PCNA): a key factor in DNA replication and cell cycle regulation. Ann Bot. 2011;107(7): $1127-40$.

35. Scholzen T, Gerdes J. The Ki-67 protein: from the known and the unknown. J Cell Physiol. 2000;182(3):311-22.

36. Chae YK, Ranganath K, Hammerman PS, Vaklavas C, Mohindra N, Kalyan A, et al. Inhibition of the fibroblast growth factor receptor (FGFR) pathway: the current landscape and barriers to clinical application. Oncotarget. 2017;8(9): 16052-74.

37. Liu Y, Shipton MK, Ryan J, Kaufman ED, Franzen S, Feldheim DL. Synthesis, stability, and cellular internalization of gold 36 nanoparticles containing mixed peptide-poly (ethylene glycol) monolayers. Anal Chem. 2007;79(6): 2221-9.

38. Duncan B, Kim C, Rotello VM. Gold nanoparticle platforms as drug and biomacromolecule delivery systems. J Control Release. 2010;148: 122-7.

39. Redko B, Tuchinsky H, Segal T, Tobi D, Luboshits G, Ashur-Fabian O, et al. Toward the development of a novel non-RGD cyclic peptide drug conjugate for treatment of human metastatic melanoma. Oncotarget. 2017; 8(1):757-68.

40. Zhang $Y$, Lin $Y$, Bowles $C$, Wang F. Direct cell cycle regulation by the fibroblast growth factor receptor (FGFR) kinase through phosphorylationdependent release of Cks1 from FGFR substrate 2. J Biol Chem. 2004; 279(53):55348-54.

41. Gérard C, Goldbeter A. The balance between cell cycle arrest and cell proliferation: control by the extracellular matrix and by contact inhibition. Interface Focus. 2014:4(3):20130075.

42. Wang M, Zhao J, Zhang L, Wei F, Lian Y, Wu Y, et al. Role of tumor microenvironment in tumorigenesis. J Cancer. 2017;8(5):761-73.

43. Kleczko EK, Heasley LE. Mechanisms of rapid cancer cell reprogramming initiated by targeted receptor tyrosine kinase inhibitors and inherent therapeutic vulnerabilities. Mol Cancer. 2018;17(1):60.

44. Wang Y, Schulte BA, Zhou D. Hematopoietic stem cell senescence and long-term bone marrow injury. Cell Cycle. 2006;5(1):35-8.

45. Gavine PR, Mooney L, Kilgour E, Thomas AP, Al-Kadhimi K, Beck S, et al. AZD4547: an orally bioavailable, potent, and selective inhibitor of the fibroblast growth factor receptor tyrosine kinase family. Cancer Res. 2012; 72(8):2045-56.
46. Gad EL, Hak H, Moawad T, Hafez G. Histological study of the effect of chemotherapy with 5-fluorouracil on Normal liver and kidney of mice. Int J Novel Res Life Sci. 2015;2:8-13.

47. Swietach P, Vaughan-Jones RD, Harris AL, Hulikova A. The chemistry, physiology and pathology of pH in cancer. Philos Trans R Soc Lond Ser B Biol Sci. 2014;369(1638):20130099.

\section{Publisher's Note}

Springer Nature remains neutral with regard to jurisdictional claims in published maps and institutional affiliations.

\section{Ready to submit your research? Choose BMC and benefit from:}

- fast, convenient online submission

- thorough peer review by experienced researchers in your field

- rapid publication on acceptance

- support for research data, including large and complex data types

- gold Open Access which fosters wider collaboration and increased citations

- maximum visibility for your research: over $100 \mathrm{M}$ website views per year

At BMC, research is always in progress.

Learn more biomedcentral.com/submissions 